\title{
APPLICATION OF INTEGRATED RESERVOIR MANAGEMENT AND RESERVOIR CHARACTERIZATION TO OPTIMIZE INFILL DRILLING
}

Cooperative Agreement Number: DE-FC22-94BC14989

FINA OIL AND CHEMICAL COMPANY

Report Date: December 12, 1995

Award Date: June 13, 1994

Anticipated Completion Dates:

Budget Period I - March 12, 1996

Budget Period II - June 12, 1999

Government Award for Budget Period I: \$1,174,264.00

Program Manager: P.K. Pande

Principal Investigator: Fina Oil and Chemical Company

Team Members

Center for Economic and Energy Diversification

David K. Davies and Associates

Fina Oil and Chemical Company

Mobil Exploration and Producing U.S. Inc. Schlumberger Well Services

Texas A\&M University

The University of Tulsa

Contracting Officer's Representative (COR):

Rhonda Lindsey, DOE Bartlesville

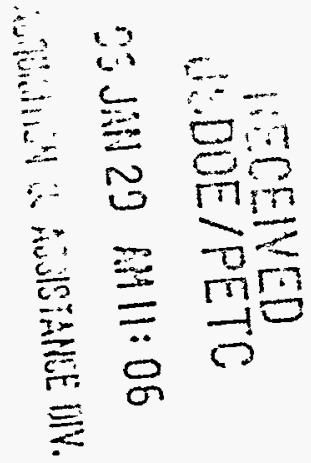

Reporting Period: September 13, 1995 - December 12, 1995

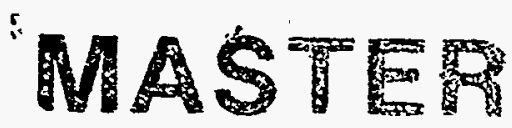


QUARTERLY TECHNICAL PROGRESS REPORT

"APPLICATION OF INTEGRATED RESERVOIR MANAGEMENT AND
RESERVOIR CHARACTERIZATION TO OPTIMIZE INFILL
DRILLING"

INSTRUMENT NO. DE-FC22-94BC14989

NORTH ROBERTSON UNIT DEPARTMENT OF ENERGY CLASS II OIL PROGRAM PROJECT

REPORTING PERIOD: 9/13/95 TO 12/12/95

This Quarterly Progress Report summarizes the technical progress of the project from 9/13/95 TO 12/12/95.

\section{ACTIVITY I.1 - MANAGEMENT AND ADMINISTRATION}

\section{PROJECT MANAGEMENT AND ADMINISTRATION - TASK I.1.1}

The main emphasis on the project during the last Quarter has been on the geostatistics and reservoir simulation in support of the Field Demonstration for Budget Period II. Assimilation of all the reservoir characterization and performance analysis data with the simulation and geostatistics was conducted to determine the specific well locations for the Field Demonstration.

\section{ACTIVITY I.2 - RESERVOIR CHARACTERIZATION AND ANALYSIS}

\section{GEOLOGICAL ANALYSIS - TASK 1.2 .1}

A Global Positioning System (GPS) survey was performed to verify the positions of the surface well locations relative to each other. This information is required in preparation for the Field Demonstration. The survey was low cost and accurate to 1.5 meters. Most of the surface locations represented on the project base maps were correct. Approximately $10 \%$ of the surface locations were incorrectly spotted with errors ranging from 50-500 feet in magnitude. Very few of these errors are within the Field Demonstration areas. Corrected surface well locations have been revised on the Unit base maps. 


\section{GEOLOGICAL ANALYSIS - TASK I.2.I (Cont'd)}

Conformance analysis is continuing by construction of interval perforation, temperature survey, and injection profile survey maps. Selected cross-sections were constructed to validate conformance improvement opportunities.

\section{RESERVOIR PERFORMANCE ANALYSIS - TASK I.2.4}

Production data for the North Robertson Unit has been analyzed using Material Balance Decline Type Curve Analysis. All primary (40-acre) and secondary (20-acre) producing wells have been analyzed to determine total/movable volumes and formation flow characteristics (permeability and skin factor) based on individual well performance. Maps of OOIP, $\mathrm{kh}$, and estimated ultimate recovery (EUR) using primary production data, and maps of kh and EUR using secondary production data have been generated and compare well with the geological interpretation. The original contacted oil-in-place has been used to calibrate each partial-unit simulation model.

Production data from an offset Clearfork waterflood was analyzed in order to estimate 10-acre infill well performance at NRU. The results of the study are shown below:

\begin{tabular}{|c|c|c|c|}
\cline { 2 - 4 } \multicolumn{1}{c|}{} & $\begin{array}{c}\text { NRU - Actual } \\
\text { 20-Acre Well } \\
\text { EUR } \\
(118 \text { wells })\end{array}$ & $\begin{array}{c}\text { NRU - Estimated } \\
\text { 10-Acre Well EUR for } \\
\text { Blanket Drilling } \\
(118 \text { wells })\end{array}$ & $\begin{array}{c}\text { NRU - Estimated } \\
\text { 10-Acre Well EUR } \\
\text { for Targeted Drilling } \\
\text { (48 wells) }\end{array}$ \\
\hline MEAN EUR & 95.8 MSTB & $76.7 \mathrm{MSTB}$ & $\sim 106.8 \mathrm{MSTB}$ \\
MAX EUR & $290.0 \mathrm{MSTB}$ & $\sim 230.0 \mathrm{MSTB}$ & $\sim 230.0 \mathrm{MSTB}$ \\
MUN EUR & $20.0 \mathrm{MSTB}$ & $\sim 20.0 \mathrm{MSTB}$ & $\sim 30.0 \mathrm{MSTB}$ \\
Ave. RF & $6.8 \%$ & $\sim 6.3 \%$ & $\sim 6.3 \%$ \\
Ave. kh & $14.9 \mathrm{md}-\mathrm{ft}$ & $\sim 16.0 \mathrm{md}-\mathrm{ft}$ & $\sim 16.0 \mathrm{md}-\mathrm{ft}$
\end{tabular}

*** - NRU 10-acre Targeted Wells in Secs. 326, 327, 329, and 362

If a 10-acre blanket drilling program was utilized, it was estimated that the average 10-acre well recovery would be reduced from 107 MSTB to 77 MSTB. Average estimated ultimate recoveries for the infill wells in the simulation model areas were between 115 MSTB and 135 


\section{RESERVOIR PERFORMANCE ANALYSIS - TASK I.2.4 (Cont'd)}

MSTB, therefore it appears that this analogy may be useful for forecasting future performance. The results of this study once again indicate the need for targeted infill drilling in SSC reservoirs.

A new waterflood/water influx performance type curve was formulated to qualitatively evaluate the performance of individual wells and patterns. The type curve is based on the analytical solutions for a well under constant pressure production with an external boundary source term (ramp or step-rate). The method is outlined in paper SPE 30774. Several of the wells in the Unit were analyzed, and it was determined that the wells are fairly well supported with respect to pressure maintenance and sweep. Unfortunately, the way in which the dimensionless variables are defined on the type curve requires that a long history of secondary production data (at least 20 to 30 years) be available to perform a comprehensive analysis. At North Robertson, we only have a 5 to 8 year history of waterflood supported production.

An additional injection well type curve is being developed to perform quantitative analysis on individual wells. It utilizes the same material balance principles that were utilized in the formulation of the type curves for producing wells. The rate plotting function ( $y$-axis) is calculated as instantaneous injection rate normalized by the change in injection pressure over time. The dimensionless time variable ( $\mathrm{x}$-axis) is calculated as cumulative water injected normalized by the instantaneous rate. These studies are nearing completion and will be presented during the next quarter.

\section{INTEGRATED RESERVOIR DESCRIPTION - TASK I.2.5}

The stratigraphic and flow unit zonation of the Unit and rock type occurrence maps are being used for the deterministic and geostatistical reservoir descriptions needed for reservoir flow simulation.

\section{GEOSTATISTICAL ANALYSIS - TASK 1.2 .6}

The geostatistical reservoir description has been generated for two modelling areas (Section 329 and 5) utilizing a stepwise approach which includes the following sequence:
- Rock Type Simulation
- Porosity Simulation
- Permeability Simulation
- Upscaling of Petrophysical Properties

The methodology is detailed below: 


\section{GEOSTATISTICAL ANALYSIS - TASK I.2.6 (Cont'd)}

Rock Type Simulation: The first step in the geostatistical reservoir description is to simulate the underlying rock types which determine the petrophysical properties. The rock type data are first transformed into categorical variables (may be represented mathematically in a "binary" type format). Isotropic and anisotropic variograms describing the spatial relationships are then generated. The anisotropic variograms provide information on the direction of maximum or minimum continuity and anisotropy ratio. Sequential gaussian simulation is then used to estimate rock type values at specific points. This involves defining a search neighborhood around sampled locations.

Porosity Simulation: For the porosity simulation only the points that have the same rock type as the unsampled points are used in the simulation process. As with the rock type simulation, spatial analyses using variograms are performed. This is followed by sequential gaussian simulation to assign porosity values as a function of rock type at unsampled locations.

Permeability Simulation: The conditional permeability distribution for each rock type is generated by plotting permeability and porosity. These permeability data are then divided into several porosity classes. For each porosity class, the cumulative conditional distribution (ccdf) of the permeability is then generated. Finally, knowing the porosity and rock type of a grid node, the ccdf plot is used to assign a random permeability to a specific grid node. In this way, all permeability data will be honored, including extreme values (i.e., high permeability streaks) that may affect reservoir performance.

Upscaling of Petrophysical Properties: Upscaling is required to assign grid block permeabilities and porosities since rock type, porosity and permeability data are generated geostatistically on a very fine grid with one foot vertical intervals. This is accomplished using a tensor method.

Geostatistical reservoir descriptions are also being generated for other modelling areas in the Field Demonstration

\section{RESERVOIR SIMULATION - TASK I.2.7}

The results of both deterministic and geostatistical reservoir simulation are being compared in the modelling areas. The goal is to ascertain the differences with the deterministic vs. the geostatistical techniques. Although it is more time consuming to obtain the reservoir description for geostatistical simulation, it should yield a more realistic representation of the actual reservoir flow mechanisms, heterogeneities, and compartmentalization which are present.

Results so far indicate that future recoveries with the deterministic reservoir descriptions is more acceleration rather than additional recovery. The reason for this is inherent in the method used 


\section{RESERVOIR SIMULATION - TASK I.2.7 (Cont'd)}

for the deterministic simulation which is a "layer-cake" based approach. Recoveries for infill drilling are lower with the geostatistical approach as this description better incorporates heterogeneity and compartmentalization.

Recoveries are similiar for a geologically targeted infill drilling pattern which employs a direct line drive, where new producers and injectors are drilled, and for a five-spot pattern where existing producers are converted to injectors and new wells drilled as producers only. However, in the case of North Robertson, development costs are nearly $25 \%$ less for equivalent or improved recoveries with the direct line drive configuration than for the five-spot pattern. In addition, the development risk in realizing the expected reserves are significantly reduced with the line drive pattern due to suspected directional fracture flow trends within the reservoir.

The deterministic simulation for Section 329, 327, and 5 have been completed. Predictive runs have been made to determine the best configurations for infill drilling. Economics have been performed on various development configurations.

\section{ACTIVITY I.3 - INTEGRATED RESERVOIR MANAGEMENT}

\section{INTEGRATED RESERVOIR MANAGEMENT - TASK L.3.1}

Well Deepenings: Twenty-two deepening candidates (10 producers, 12 injectors) were previously identified based on geological and engineering reservoir characterization of the North Robertson Unit. All these wells appeared to have recompletion potential by adding additional perforations in the lower Clearfork, although all the wells are along the shelf-edge on the northern side of the Unit in an area where there was little data for interpretation, i.e., no modern logs and no rock-type solutions. The majority of these wells were in the northwest area of the Unit (Section 329).

The deepening candidates were identified and ranked on the basis of their relative $k h$ potentials from extrapolation of the rock-log model $k h$ data to unsampled locations on the edges of the Unit. All of the wells were original 40-acre producers, so wellbore integrity was a major concern. Past experiences indicated that these lower Clearfork intervals may have been water producers in Section 329, therefore, a well to the southeast in Section 324 (NRU 3603) was chosen as the first deepening candidate. Subsequent decisions regarding whether to proceed northwest or southeast along the shelf-edge were based on the success of this first deepening. 


\section{INTEGRATED RESERVOIR MANAGEMENT - TASK I.3.1 (Cont'd)}

\section{Well NRU 3603 Results}

NRU 3603 was deepened approximately 100 feet during July, 1995. Whole core was obtained across the entire interval, and a comprehensive suite of open-hole log surveys were recorded, including:

- Fluid Saturation Determination

- Dual Laterolog

- Compensated Neutron

- Compensated Density/PE/Caliper

- $200 \mathrm{MHz}$ Dielectric

- Rock Mechanical Properties (Fracture Design)

- Digital Array Sonic

\section{- Borehole Imaging Log}

The log and core analysis both indicated potential pay over approximately $40 \%$ of the deepened section. The well was producing 7 STBO/D and $1 \mathrm{BW} / \mathrm{D}$ prior to the deepening. It currently produces approximately $13 \mathrm{STBO} / \mathrm{D}$ and $150 \mathrm{BW} / \mathrm{D}$. Early production after the deepening was intermittent due to problems caused by repeated pump failure due to the presence of frac sand in the wellbore and various other mechanical problems. The well has been on fairly continuous production since the beginning of December 1995. It is encouraging that the total fluid rate has been increased significantly, and this deepening cannot be considered a failure until the well stays on production for a longer period of time as the oil rate may eventually increase after clean-up.

\section{Future Deepenings}

The results of this well deepening appear to confirm our suspicions about the lower Clearfork section in the northwest region of the Unit. Subsequent reservoir simulation studies in Section 329 have shown that this interval is a major water producer. Further well deepening activities will most likely be limited to wells southeast of NRU 3603. The petrophysical data analyses, the results of which were utilized to design this well completion, have provided us with valuable information for our future data acquisition and analysis programs during Budget Period II.

Pressure Transient Tests: Pressure transient (buildup and falloff) data are being used to estimate reservoir pressure and formation flow characteristics. The estimated bottomhole pressures from buildup surveys conducted during 1985-1991 and the current pressure falloff and buildup tests have been tabulated for use in the geostatistical analysis and reservoir simulation. 


\section{INTEGRATED RESERVOIR MANAGEMENT - TASK I.3.1 (Cont'd)}

The analyses of the buildup tests indicate that the hydraulic fracture treatments were relatively ineffective (short fracture half-lengths) in creating good pressure sinks at the wellbore due to the presence of large, discontinuous gross pay intervals containing many individual layers, and possessing no effective barriers to vertical fracture propagation. Future completions, stimulations, and hydraulic frac jobs will target specified pay intervals as defined by the core/log model in order to improve completion efficiency and interwell conformance.

Pressure Build-Up Tests: Additional bottomhole pressure buildup surveys are presently being recorded throughout the Unit to provide further data for pressure matching during reservoir simulation, and to locate areas of the reservoir (if any) which have not been effectively repressured. The use of a new pressure data acquisition technique for several of the tests, in which data is sent uphole real-time using radio signals via the wellbore strata, has been extremely useful in returning wells to production as soon as the required amount of data is obtained. The system can also be used to curtail or terminate tests for which no useful data is being obtained (i.e., packer leak, bad downhole gauge, etc.). It is felt that the use of this emerging technology is in keeping with the goals of this project for the identification of such techniques. The cost of the survey is about the same as the usual pressure buildup test. A schematic of the telemetry acquisition system is shown below:

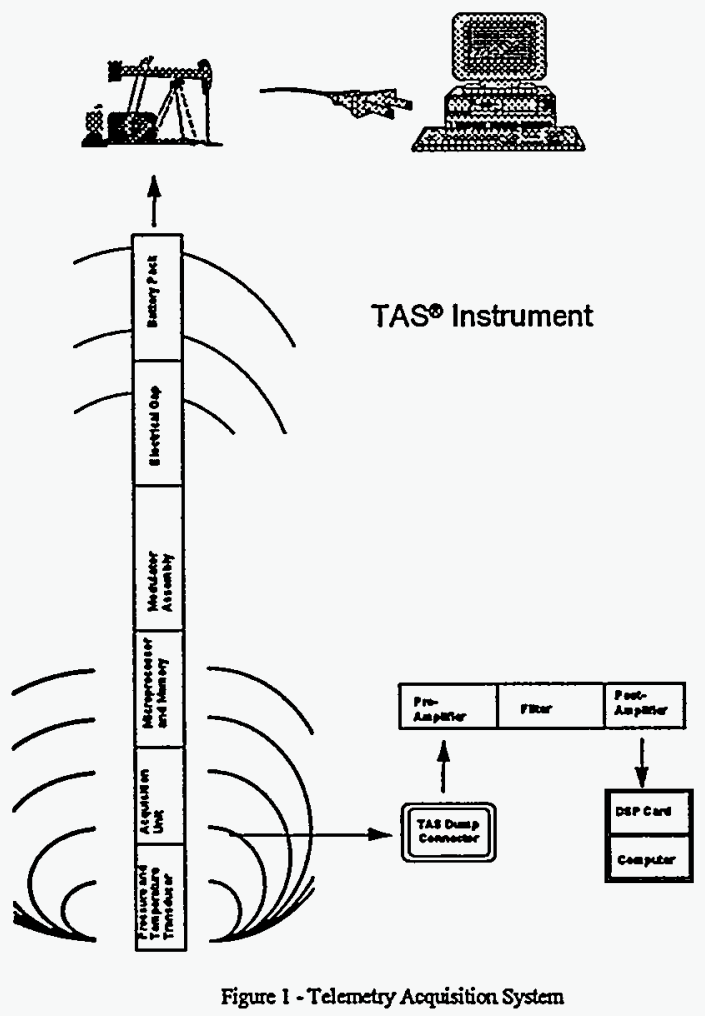




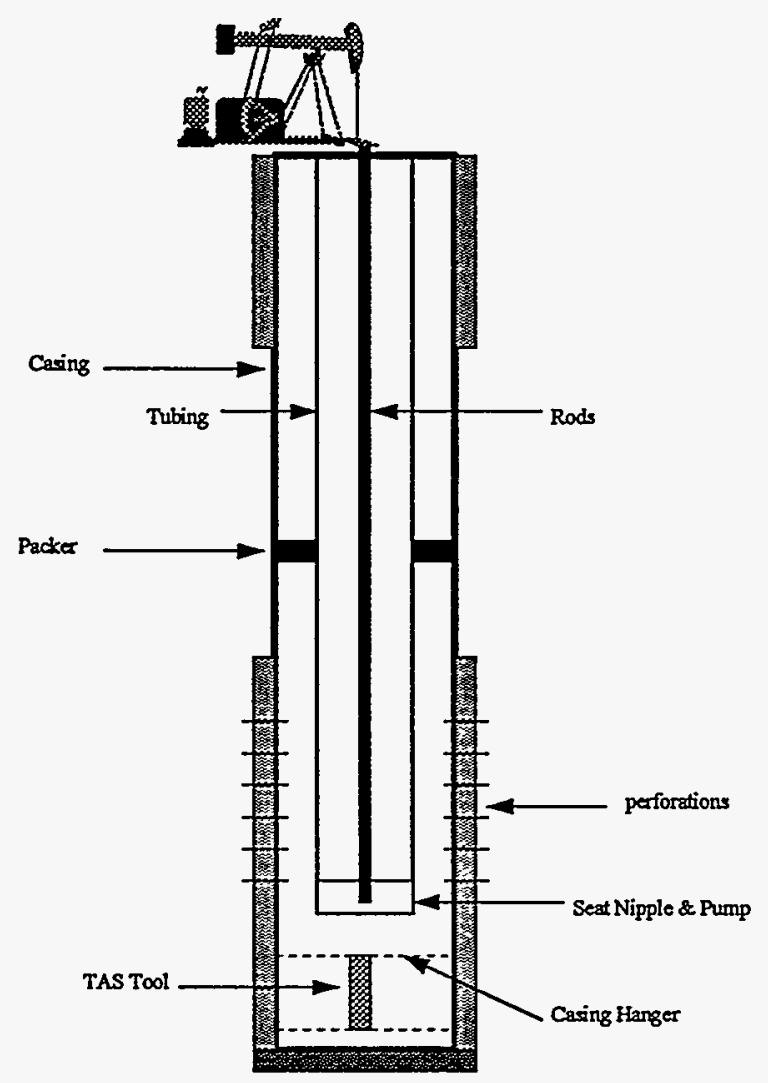

Figure 2 - Downhole Configuration for NRU Pressure Buildup Tests.

In addition, in some future tests both surface and downhole pressure acquisition techniques will be used in order to compare the relative data quality from both test types. By measuring the surface pressure and monitoring fluid level height during the test, a buildup can be performed without the cost associated with pulling a well to run downhole shut-in devices. One of the major goals of our pressure buildup program to date has been to set up a good baseline data set using downhole shut-ins. We can then monitor these wells in a cost-effective manner by performing future tests from surface, when possible. However, as wellbore fill is almost always a major problem in this area, it is always a good idea to tag the fill or clean out the well prior to testing in order to acquire representative data.

Eight pressure buildup tests have been completed, and three more are planned for the first quarter of 1995. Initial results indicate that the average reservoir pressure in the areas surrounding the producing wells is approximately 2850 psia, and the pressure level appears to be directly 


\section{INTEGRATED RESERVOIR MANAGEMENT - TASK 1.3.1 (Cont'd)}

correlated to the rate of fluid withdrawal. We will run pressure buildups over specific intervals on the new infill wells in order to identify the formation flow characteristics of each major formation (Lower, Middle, Upper Clearfork and Glorieta). This is not possible on the existing wells since we cannot isolate individual zones due to the operational problems involved with running a packer through existing perforations.

In addition, individual layer pressures will be obtained on the new wells using formation test tools (RFT, MDT) as part of the open-hole logging program.

Pressure Falloff Tests: Ten tests have been completed using surface pressure data acquisition. Initial results show that the current reservoir pressure in areas around the injection wells is approximately 3400 psia. All of the injection wells analyzed appear to be well stimulated, however, this is most likely the result of extensive fracture propagation due to continuous injection at or near the fracture pressure of the formation. A few tests indicate that offset injection wells may be in contact with each other via hydraulic fractures. Falloff data acquisition will continue in order to quantify the manner in which the reservoir is being repressured and to get as much usable data as possible for simulation history matching and subsequent infill drilling.

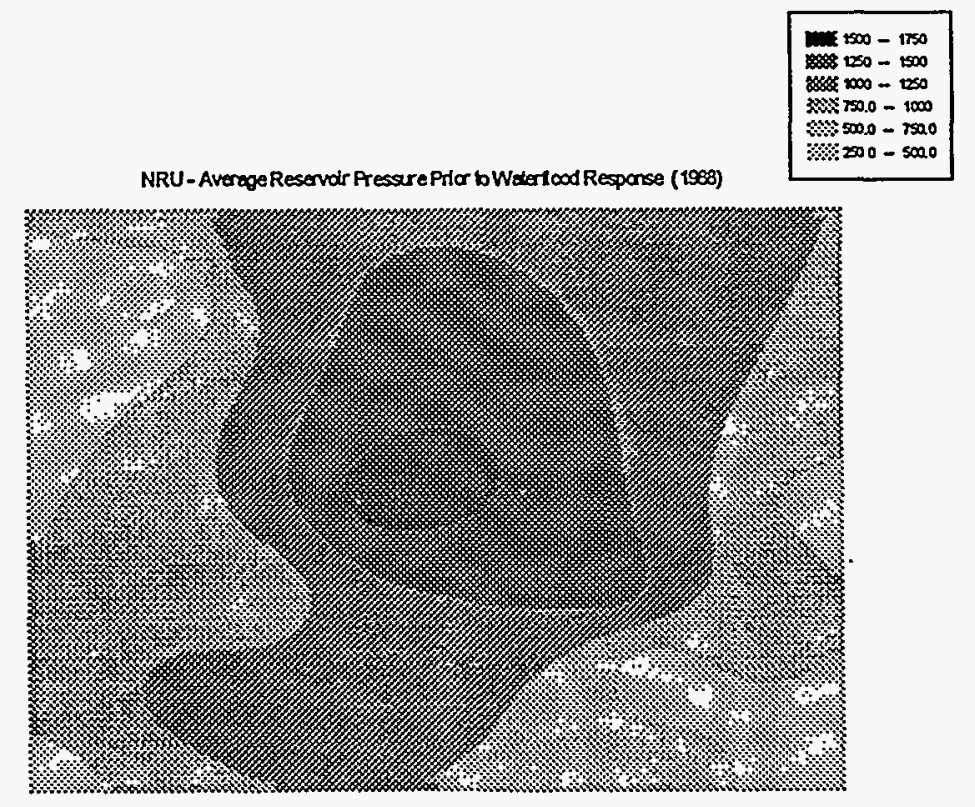

Figure 3 - Map Of Average Reservoir Pressure (psia) Prior to Waterflood Response (1988) 


\section{INTEGRATED RESERVOIR MANAGEMENT - TASK L.3.1 (Cont'd)}

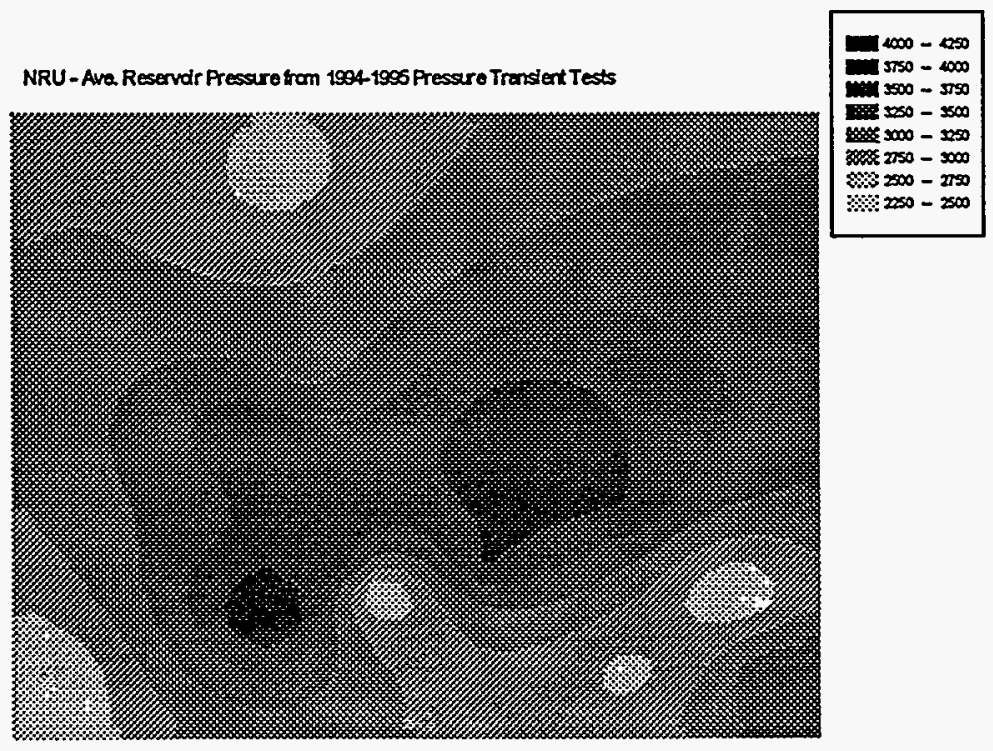

\section{Figure 4 - Map Of Current Average Reservoir Pressure (psia)}

Completions/Stimulations/Hydraulic Fracturing: New stimulation and fracturing techniques are currently being evaluated as we meet with individual service companies in order to identify optimum methods for completion and stimulation prior to drilling 10-acre infill wells. A stimulation database has been set up to determine which stimulation methods, fluids, and volumes produce the best completions. At this point, we feel that utilizing foam fracs $\left(\mathrm{CO}_{2}\right)$, reducing the size of the treated intervals, and using cluster perforating rather than the limited-entry type treatment that was done in the past, will yield very good results. Some of the offset operators in the area have used these techniques with great success in the recent past. Further studies will be conducted in the next quarter prior to the Field Demonstration phase of the project.

TDT Logging: The evaluation of the current water saturation profile throughout the Unit is being done using Thermal Decay Time (TDT) logs. The new data has been compared with original water saturation data for reservoir surveillance purposes, and is being used to set up a "baseline" data set for future surveillance work. Eight surveys have been completed to date, and two more will be completed during the first quarter of 1996. At this time, it is expected that three of the new infill wells will also have base TDT logs recorded on them for future surveillance purposes. 


\section{INTEGRATED RESERVOIR MANAGEMENT - TASK I.3.1 (Cont'd)}

Production Logging: The TDT may also be used in conjunction with a production logging survey to identify zones which contribute most to production, and to verify or disprove previous conclusions regarding the relative contributions of the Glorieta, Upper, Middle, and Lower Clearfork. Since these wells do not produce naturally (pumping wells), wells with fairly high fluid levels will be chosen and the downhole pump will be moved above the top of the producing interval. A tracer/temperature/fluid capacitance tool will be run down the tubing-casing annulus, and the well will be put on production. Estimates of individual zone contributions will hopefully be obtained by injecting radioactive tracer and following it uphole to determine relative rates from each perforated interval.

An earlier test was performed in which flow was induced by injecting nitrogen to create an artificial pressure drop in the area of a downhole packer-type flowmeter tool. This survey was unsuccessful due to the inability to initiate a stable flow rate. After review, it was felt that this was not a cost-effective method for obtaining production profiles as it involved a complicated and expensive equipment set-up.

ACTIVITY I.4 - ECONOMIC EVALUATION AND FIELD DEMONSTRATION RECOMMENDATION

ECONOMIC EVALUATION AND FIELD DEMONSTRATION RECOMMENDATION TASK I.4.1

Rate-time projections being developed from the reservoir flow simulation, reservoir performance analyses, and other work are being used to generate discounted cash-flow economics in support of the well locations for the Field Demonstration. Other economic measures such as $\$ / \mathrm{Bbl}$ development cost are also being considered in the economic evaluation.

\section{ACTIVTTY I.5 - TECHNOLOGY TRANSFER}

\section{NEWSLETTERS - TASK 1.5 .2}

Approximately 1000 copies of the Project Newsletter have been distributed. The Newsletter was well received by industry. The next Newsletter will be developed and distributed during Budget Period II.

\section{PUBLICATIONS AND PRESENTATIONS - TASK 1.5.3}

Technology transfer activities for the project this Quarter were: 


\section{PUBLICATIONS AND PRESENTATIONS - TASK I.5.3 (Cont'd)}

\section{Published Papers and Professional Meeting Presentations:}

- SPE Annual Technical Conference and Exhibition, October 22-25, 1995, Dallas, TX.

SPE 30774, "Decline Curve Analysis Using Type Curves: Water Influx/Waterflood Cases."

SPE 30601, "Simulation of Geological Model Using Multipoint Histogram."

\section{TECHNICAL WORKSHOPS - TASK 1.5 .5}

The first technology transfer workshop is scheduled in Midland, Texas for March 14-15, 1995. A subsequent workshop will be scheduled for Houston.

\section{DISCLAIMER}

This report was prepared as an account of work sponsored by an agency of the United States Government. Neither the United States Government nor any agency thereof, nor any of their employees, makes any warranty, express or implied, or assumes any legal liability or responsibility for the accuracy, completeness, or usefulness of any information, apparatus, product, or process disclosed, or represents that its use would not infringe privately owned rights. Reference herein to any specific commercial product, process, or service by trade name, trademark, manufacturer, or otherwise does not necessarily constitute or imply its endorsement, recommendation, or favoring by the United States Government or any agency thereof. The views and opinions of authors expressed herein do not necessarily state or reflect those of the United States Government or any agency thereof. 